\title{
Evidence on Night Movements of Macroinvertebrates to Macrophytes in a Pampean Stream
}

\author{
Nicolás Ferreiro1,2 \\ ${ }^{1}$ Instituto de Ecología y Desarrollo Sustentables (INEDES) and Departamento de Ciencias Básicas, Universidad \\ Nacional de Luján, Luján, Argentina \\ ${ }^{2}$ Consejo Nacional de Investigaciones Científicas y Tecnológicas (CONICET), Buenos Aires, Argentina \\ Email: nicolasferreiro@conicet.gov.ar
}

Received 20 April 2014; revised 19 May 2014; accepted 20 June 2014

Copyright (C 2014 by author and Scientific Research Publishing Inc.

This work is licensed under the Creative Commons Attribution International License (CC BY).

http://creativecommons.org/licenses/by/4.0/

(c) (i) Open Access

\begin{abstract}
Nocturnal invertebrate abundance peaks in lotic systems are usually associated to drift, however, diel migrations other than drift may be important in slow-flowing systems. Then, macroinvertebrate distribution on macrophytes may change along the day as result of vertical or horizontal migration from sediments or the water column. My objective was to determine whether macroinvertebrate abundance on macrophytes changes along $24 \mathrm{~h}$. Three Ceratophyllum demersum patches were sampled in late spring from the Las Flores stream (Central Argentina) at 11:20 h, 17:10 $\mathrm{h}, 23: 00 \mathrm{~h}$ and 5:00 $\mathrm{h}$. Macroinvertebrates were counted and identified, and relative abundances were estimated for each sampling time. The dominant groups of macroinvertebrates sampled were Oligochaeta, Amphipoda and Cladocera. The relative abundance of macroinvertebrates on macrophytes was the highest at 5:00 $\mathrm{h}$, when dissolved oxygen in water reached its minimum. In conclusion, the abundance of macroinvertebrates on macrophytes in Pampean streams may increase at night, probably as result of nocturnal migration driven by changes in predation risk or dissolved oxygen.
\end{abstract}

\section{Keywords}

Night Movements, Oligochaeta, Aquatic Plants, Lotic Ecosystem, Dissolved Oxygen

\section{Introduction}

The darkness is an environmental condition that is as important as light to almost all living organisms, however, 
it is frequently understudied due to logistical problems. In aquatic systems, its study is particularly important because light limitation usually exists. In any case, aquatic organisms which activity is affected by light and dark cycles are relevant because they are often herbivores eaten by fishes [1], or they are fishes themselves [2].

In lotic and lentic environments, the study of darkness effect on macroinvertebrate activity has been approached in different ways. While in lotic systems it has long been recognized the existence of a nocturnal peak in drift rates [3] [4], in lentic systems the existence of diel vertical migration is well known [5]. In both cases, night movements are associated with a behavioral change which is mainly explained by differences in light intensity [2] [6], although some have also reported oxigen driven (Wiley \& Kohler, 1980) and endogenous behavioral changes [7]. Regarding the adaptative meaning, the hypothesis of darkness providing refuge from predators is the most accepted [1] [2]. On the other hand, since natural light and dark cycles have existed throughout evolutionary time, many organisms may have evolved behaviors that are cued by or are dependent upon darkness, like foraging and reproductive behaviors [8].

In Pampean streams, the lack of riparian forest, low current velocity and high nutrient concentration allow the development of abundant and diverse patches of aquatic plants [9] which provide special environmental conditions that may affect organisms behavior during night, as it has been reported for lakes [10]. In addition, low current velocity may reduce the importance of drift for invertebrates that, having greater movement autonomy, may be able of a nocturnal migration analogous to that reported for lentic environments.

The objective of this study was to estimate the variation in macroinvertebrate abundance on macrophytes along $24 \mathrm{~h}$ in a Pampean stream. The working hypothesis was that in Pampean streams there is an increase in epiphytic macroinvertebrate abundance at night, suggesting the existence of nocturnal migrations.

\section{Methods}

The study was conducted in the Las Flores stream, a second-order stream that is a tributary of the Luján River $\left(34^{\circ} 27^{\prime} 25^{\prime \prime} \mathrm{S}, 59^{\circ} 03^{\prime} 56^{\prime \prime} \mathrm{W}\right)$. The stream is situated in the Pampean region, a vast grassy plain that covers central Argentina, where the climate is temperate humid with a mean annual temperature of $16^{\circ} \mathrm{C}$, and a mean annual precipitation between 600 and $1200 \mathrm{~mm}$. The Las Flores stream is a naturally nutrient-rich stream $(\mathrm{SRP} \approx 0.8$ $\mathrm{mg} \cdot \mathrm{l}^{-1}$ and nitrates $\left.\approx 4 \mathrm{mg} \cdot \mathrm{l}^{-1}\right)$ with low current velocity $\left(\approx 20 \mathrm{~cm} \cdot \mathrm{sec}^{-1}\right)$ and well oxygenated water $\left(\approx 8 \mathrm{mg} \cdot \mathrm{l}^{-1}\right)$ [11]. The studied reach was well preserved, although some cattle breeding was being developed in the surrounding area.

Three monospecific patches of Ceratophyllum demersum L., one of the commoner submerged macrophyte species in the stream, distributed along a $30 \mathrm{~m}$ reach $(0 \mathrm{~m}, 18 \mathrm{~m}$ and $30 \mathrm{~m})$ were sampled at 11:20 h, 17:10 h, 23:00 $\mathrm{h}$ and 5:00 $\mathrm{h}$ in 4th and 5th December 2010 (sunrise: 5:34 h and sunset: 19:54 h). At each sampling time, temperature, dissolved oxygen concentration, conductivity and $\mathrm{pH}$ in water were measured (Table 1). Macrophytes and associated macroinvertebrates were collected with $1000 \mathrm{~mL}$ plastic containers which were fast moved until about $20 \mathrm{~cm}$ of the plant were introduced inside. Then, containers were closed cutting the plant stems off. Macrophyte samples were taken close to the stream surface and patch edge, avoiding senescent shoots. At the laboratory, macrophyte samples were rinsed off to remove macroinvertebrates, which were preserved in $70 \%$ alcohol for identification and counting under stereoscopic microscope. Macrophytes were dried at $60^{\circ} \mathrm{C}$ until constant weigh to estimate macroinvertebrate density per macrophyte gram. I refer to the number of taxa and not the number of species because of the difficulty in identifying aquatic macroinvertebrates in this system and the fact that taxonomic resolution varied among groups. The macroinvertebrate relative abundance was estimated per each sampling time.

Table 1. Physico-chemical parameters measured at each sampling time.

\begin{tabular}{ccccc} 
& $\begin{array}{c}12 / 4 / 2010 \\
11: 20 \mathrm{~h}\end{array}$ & $\begin{array}{c}12 / 4 / 2010 \\
17: 10 \mathrm{~h}\end{array}$ & $\begin{array}{c}12 / 4 / 2010 \\
23: 00 \mathrm{~h}\end{array}$ & $\begin{array}{c}12 / 5 / 2010 \\
5: 00 \mathrm{~h}\end{array}$ \\
\hline Temperature $\left({ }^{\circ} \mathrm{C}\right)$ & 24.3 & 27.6 & 22.8 & 20.4 \\
Conductivity $\left(\mu \mathrm{S} \cdot \mathrm{cm}^{-1}\right)$ & 839 & 810 & 842 & 842 \\
$\mathrm{pH}$ & 8.39 & 8.81 & 8.04 & 7.69 \\
Dissolved oxygen concentration $\left(\mathrm{mg} \cdot \mathrm{l}^{-1}\right)$ & 19.96 & 21.71 & 5.35 & 1.83 \\
\% Saturation & 240.2 & 277.8 & 62.5 & 20.4 \\
\hline
\end{tabular}


Since great differences in abundance were registered between patches at each sampling occasion, the effect of time on invertebrate abundance was evaluated by one-way block ANOVA, using invertebrate abundance as variable, time as factor and blocking by patch. The relative abundance of macroinvertebrates was calculated dividing the number of invertebrate sampled at each time by the sum of invertebrate abundances in all times, for each patch (Nurminen \& Horppila 2002). All variables were checked for normality (Shapiro-Wilk, p > 0.05) and homogeneity of variances (Levene, $\mathrm{p}>0.05$ ) before parametric tests were performed. Variables that did not meet the assumption of normality were log-transformed.

\section{Results}

The macroinvertebrate community included 24 taxa, comprising 4 genera, 11 families and 9 major groups and was dominated by Oligochaeta (58\% of total individuals; mean of the three patches). Other groups such as Amphipoda (9\%), Cladocera (7\%), Copepoda (6\%), Odonata (5\%) and Ephemeroptera (3\%) were also present. Not only epiphytic organisms but also planktonic invertebrates like Cladocera (Daphnia sp.), Copepoda (Calanoida) and Ostracoda were present in the samples (Table 2).

A great variation among macrophyte patches for each sampling time and among sampling times for each patch was found in macroinvertebrate density (Figure 1) and relative abundance (Figure 2). Significant differences were found among sampling times in macroinvertebrate relative abundance (ANOVA, $\mathrm{F}=5.149, \mathrm{p}=$ 0.028) but not in macroinvertebrate density (one-way ANOVA for time factor and one-way ANOVA for patch factor, $\mathrm{p}>0.05$ ). The effect of time on macroinvertebrate relative abundance was caused by the higher number of individuals found at 5:00 h than at 17:10 h (Tukey a posteriori multiple comparisons, $\mathrm{p}=0.031$ ). A consistent variation in macroinvertebrate abundance was detected along the day, with a minimum at 17:10 $\mathrm{h}$ and a maximum at 5:00 h in groups like Oligochaeta, Copepoda and Ephemeroptera (Figure 3).

\section{Conclusions}

As for macroinvertebrate taxa found, the abundance of planktonic organisms such as Cladocera, Copepoda and Ostracoda was surprising. However, it has been previously reported the presence of Cladocera highly associated to macrophytes in lentic systems [10].

The abundance of macroinvertebrates showed a maximum during the night sampling at 5:00 h (Figure 1). From Tukey multiple comparisons, which showed significant differences between samplings at 17:10 h and 5:00 h, and Figure 1, it is possible to state that the nocturnal increment in abundance does not produce gradually but in a pretty abrupt way once the sun sets. Oligochaeta and Ephemeroptera, among epiphytic organisms, as well as Cladocera and Copepoda, among planktonic, may be which most likely are giving place to the increase in total abundance during the night (Table 2). The comparison between epiphytic, planktonic and benthonic organ-

a)

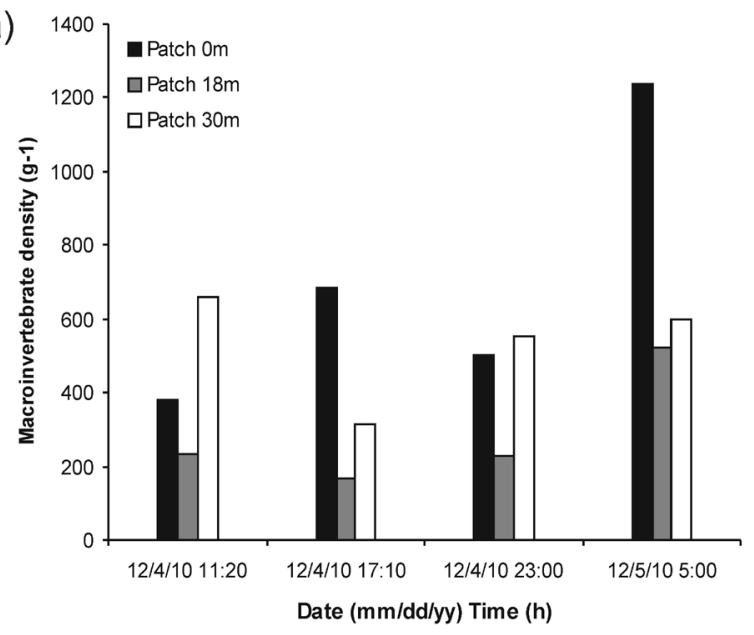

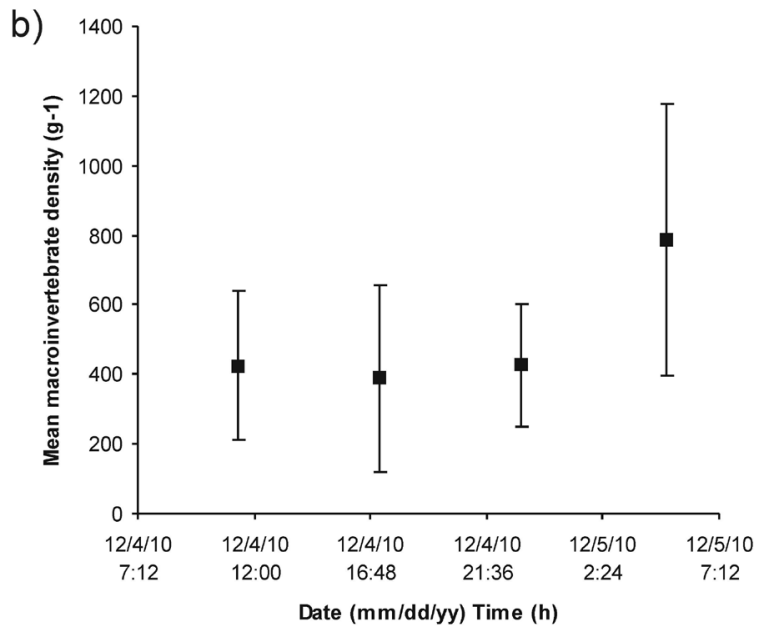

Figure 1. a) Macroinvertebrate density $\left(\mathrm{g}^{-1}\right)$ discriminated by patch and sampling time, b) Mean macroinvertebrate density $\left(\mathrm{g}^{-1}\right)$ discriminated by sampling time. Error bars $=1$ standard deviation. 
Table 2. Macroinvertebrate density $\left(\mathrm{g}^{-1}\right)$ discriminated by taxon and sampling time. Figures represent mean values and (between brackets) standard deviations of the three patches sampled.

\begin{tabular}{|c|c|c|c|c|c|}
\hline Taxon & $\begin{array}{c}12 / 4 / 2010 \\
11: 20 \mathrm{~h}\end{array}$ & $\begin{array}{c}12 / 4 / 2010 \\
17: 10 \mathrm{~h}\end{array}$ & $\begin{array}{c}12 / 4 / 2010 \\
23: 00 \mathrm{~h}\end{array}$ & $\begin{array}{c}12 / 5 / 2010 \\
5: 00 \mathrm{~h}\end{array}$ & All sampling times \\
\hline \multicolumn{6}{|l|}{ Mollusca } \\
\hline \multicolumn{6}{|l|}{ Gastropoda } \\
\hline Chilinidae, Chilina & $0( \pm 1)$ & $0( \pm 0)$ & $0( \pm 0)$ & $0( \pm 0)$ & $0( \pm 1)$ \\
\hline Hydrobiidae, Heleobia & $0( \pm 0)$ & $0( \pm 0)$ & $0( \pm 0)$ & $6( \pm 10)$ & $6( \pm 10)$ \\
\hline \multicolumn{6}{|l|}{ Annelida } \\
\hline Hirudinea & $1( \pm 2)$ & $0( \pm 0)$ & $1( \pm 1)$ & $1( \pm 1)$ & $3( \pm 4)$ \\
\hline Oligochaeta & $355( \pm 204)$ & $310( \pm 256)$ & $310( \pm 209)$ & $410( \pm 263)$ & $1385( \pm 769)$ \\
\hline Hidrachnida & $2( \pm 1)$ & $1( \pm 1)$ & $0( \pm 0)$ & $2( \pm 3)$ & $5( \pm 5)$ \\
\hline \multicolumn{6}{|l|}{ Crustacea } \\
\hline \multicolumn{6}{|l|}{ Amphipoda } \\
\hline Hyalellidae, Hyallela & $44( \pm 10)$ & $47( \pm 13)$ & $57( \pm 5)$ & $68( \pm 7)$ & $216( \pm 9)$ \\
\hline Cladocera, Daphnia & $9( \pm 6)$ & $37( \pm 60)$ & $25( \pm 29)$ & $103( \pm 129)$ & $175( \pm 222)$ \\
\hline Copepoda: Calanoida & $40( \pm 35)$ & $20( \pm 12)$ & $28( \pm 9)$ & $63( \pm 42)$ & $150( \pm 89)$ \\
\hline Ostracoda & $12( \pm 9)$ & $10( \pm 12)$ & $3( \pm 1)$ & $16( \pm 6)$ & $41( \pm 21)$ \\
\hline \multicolumn{6}{|l|}{ Insecta } \\
\hline Coleoptera & $3( \pm 1)$ & $1( \pm 1)$ & $3( \pm 1)$ & $3( \pm 2)$ & $9( \pm 3)$ \\
\hline \multicolumn{6}{|l|}{ Diptera } \\
\hline Chironomidae & $24( \pm 4)$ & $25( \pm 11)$ & $24( \pm 16)$ & $21( \pm 10)$ & $93( \pm 29)$ \\
\hline Culicidae & $1( \pm 1)$ & $0( \pm 1)$ & $1( \pm 1)$ & $2( \pm 1)$ & $4( \pm 1)$ \\
\hline \multicolumn{6}{|l|}{ Ephemeroptera } \\
\hline Caenidae, Caenis & $9( \pm 6)$ & $8( \pm 6)$ & $9( \pm 5)$ & $24( \pm 13)$ & $50( \pm 7)$ \\
\hline Baetidae & $10( \pm 15)$ & $1( \pm 2)$ & $2( \pm 3)$ & $2( \pm 1)$ & $15( \pm 21)$ \\
\hline \multicolumn{6}{|l|}{ Hemiptera } \\
\hline Belostomatidae & $0( \pm 0)$ & $1( \pm 1)$ & $0( \pm 0)$ & $2( \pm 1)$ & $3( \pm 2)$ \\
\hline Corixidae & $0( \pm 0)$ & $0( \pm 0)$ & $0( \pm 0)$ & $0( \pm 1)$ & $1( \pm 1)$ \\
\hline Gelastocoridae & $4( \pm 3)$ & $9( \pm 10)$ & $12( \pm 8)$ & $9( \pm 8)$ & $34( \pm 21)$ \\
\hline Notonectidae & $0( \pm 0)$ & $1( \pm 1)$ & $0( \pm 0)$ & $0( \pm 1)$ & $2( \pm 2)$ \\
\hline Ranatridae & $0( \pm 0)$ & $0( \pm 1)$ & $0( \pm 0)$ & $0( \pm 0)$ & $1( \pm 0)$ \\
\hline Velidae & $1( \pm 1)$ & $0( \pm 0)$ & $0( \pm 0)$ & $0( \pm 0)$ & $1( \pm 1)$ \\
\hline \multicolumn{6}{|l|}{ Odonata } \\
\hline Anisoptera & $1( \pm 1)$ & $0( \pm 0)$ & $0( \pm 1)$ & $0( \pm 0)$ & $1( \pm 1)$ \\
\hline Zigoptera, Coenagrionidae & $17( \pm 4)$ & $31( \pm 7)$ & $41( \pm 28)$ & $38( \pm 15)$ & $127( \pm 43)$ \\
\hline \multicolumn{6}{|l|}{ Trichoptera } \\
\hline Hydroptilidae & $7( \pm 10)$ & $6( \pm 8)$ & $16( \pm 24)$ & $18( \pm 21)$ & $48( \pm 64)$ \\
\hline Nematomorpha & $0( \pm 0)$ & $0( \pm 1)$ & $1( \pm 1)$ & $0( \pm 0)$ & $1( \pm 2)$ \\
\hline All taxa & $541( \pm 244)$ & $510( \pm 363)$ & $533( \pm 279)$ & $788( \pm 390)$ & $2372( \pm 1069)$ \\
\hline
\end{tabular}

isms, plus an assessment of macroinvertebrate abundance in water and sediment, may allow in future studies to distinguish between nocturnal horizontal migration to macrophytes, already reported in lakes (Nurminen \& Horppila 2002), and nocturnal vertical migration to macrophytes, which may exist in low current streams.

As for the variables that may be capable of triggering such nocturnal movements in macrophyte patches from Pampean streams, we should add to the classic effect of light [2] [6] a possible influence of great differences in dissolved oxygen (21.71 mg.l $l^{-1}$ at 17:10 h and $1.83 \mathrm{mg} \cdot \mathrm{l}^{-1}$ at 5:00 h, Table 1 ), as low oxygen concentrations have also been suggested as capable of enhancing drift [12]. Finally, the adaptative meaning of horizontal migrations of planktonic organisms like Cladocera and vertical migrations of epiphytic/benthonic organisms like Oligochaeta, during the night, may be in protection from predators [1]. On the other hand, since these aquatic 
a)

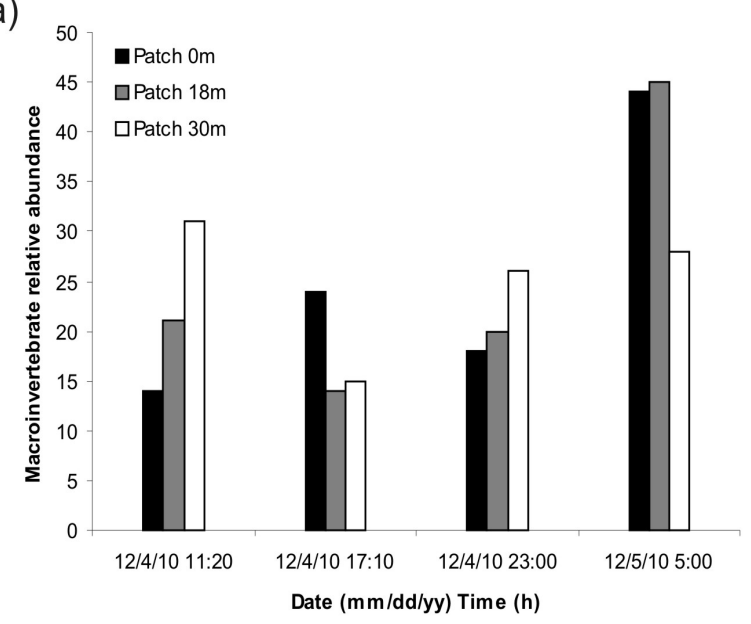

b)



Figure 2. a) Relative abundance of macroinvertebrates during samplings discriminated by patch and sampling time, b) Mean relative abundance of macroinvertebrates during samplings discriminated by sampling time. Error bars $=1$ standard deviation.

a)

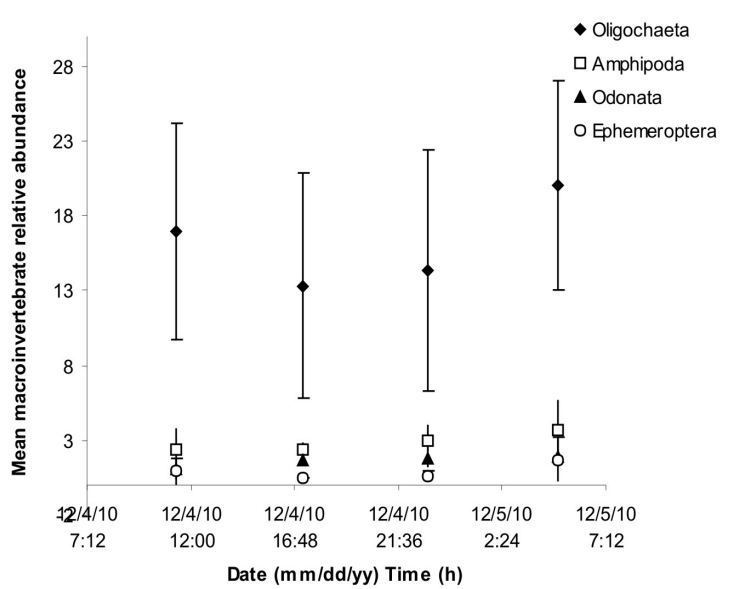

b)

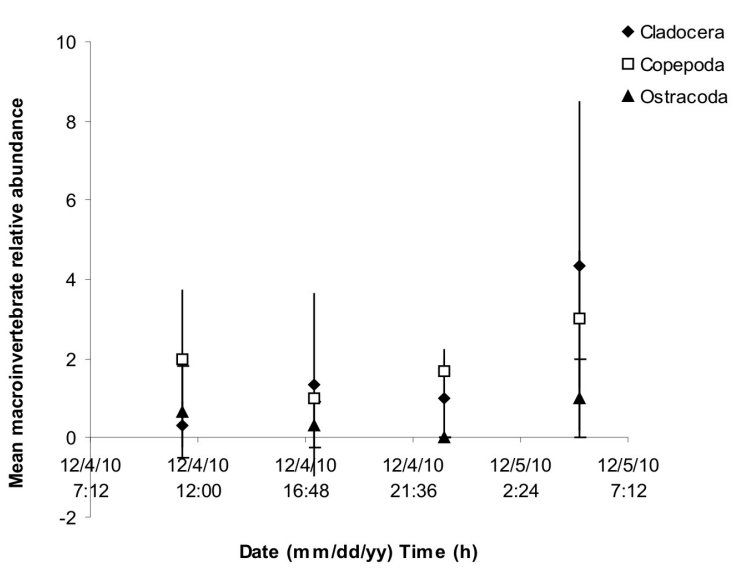

Figure 3. a) Mean relative abundance of main epiphytic macroinvertebrate groups during samplings discriminated by taxon and sampling time, b) Mean relative abundance of planktonic macroinvertebrate groups during samplings discriminated by taxon and sampling time. Error bars $=1$ standard deviation.

plants have great biomasses of biofilm and detritus [13], food resource for Oligochaeta, Amphipoda and Ephemeroptera, we can not discard the simultaneous existence of a preferably nocturnal feeding behavior.

In conclusion, these results support the hypothesis of increase in macroinvertebrates abundance during the night. However, the low number of replicates plus the high environmental variability did not allow conclude much about the specific groups of invertebrates involved. In addition, further simultaneous research on macrophyte, sediment and water column macroinvertebrate abundances along a day are necessary to test the existence of nocturnal horizontal or vertical migration in Pampean streams.

\section{Acknowledgements}

The author is grateful to the landowner of the farm, Mr. Solá, for providing access to the study site. This project was supported by the Universidad Nacional de Luján.

\section{References}

[1] Flecker, A.S. (1992) Fish Predation and the Evolution of Invertebrate Drift Periodicity: Evidence from Neotropical 
Streams. Ecology, 73, 438-448. http://dx.doi.org/10.2307/1940751

[2] Scheuerell, M.D. and Schindler, D.E. (2003) Diel Vertical Migration by Juvenile Sockeye Salmon: Empirical Evidence for the Antipredation Window. Ecology, 84, 1713-1720. http://dx.doi.org/10.1890/0012-9658(2003)084[1713:dvmbjs]2.0.co;2

[3] Elliot, J.M. (1967) Invertebrate Drift in a Dartmoor Stream. Archiv für Hydrobiologie, 63, 202-237. http://dx.doi.org/10.1038/2051127c0

[4] Brittain, J.E. and Eikeland, T.J. (1988) Invertebrate Drift—A Review. Hydrobiologia, 166, 77-93. http://dx.doi.org/10.1007/bf00017485

[5] Hays, G.C. (2003) A Review of the Adaptive Significance and Ecosystem Consequences of Zooplankton Diel Vertical Migrations. Hydrobiologia, 503, 163-170. http://dx.doi.org/10.1007/978-94-017-2276-6 18

[6] Bishop, J.E. (1969) Light Control of Aquatic Insect Activity and Drift. Ecology, 50, 371-380. http://dx.doi.org/10.2307/1933885

[7] Chaston, I. (1969) A Comparison of the Activity Patterns of the Aquatic Larvae Protonemura meyeri (Plecoptera) and Chaoborus punctipennis (Diptera). The American Midland Naturalist Journal, 82, 302-307. http://dx.doi.org/10.2307/2423847

[8] Gerrish, G.A., Morin, J.G., Rivers, T.J. and Patrawala, Z. (2009) Darkness as an Ecological Resource: The Role of Light in Partitioning the Nocturnal Niche. Oecologia, 160, 525-536. http://dx.doi.org/10.1007/s00442-009-1327-8

[9] Feijoó, C. and Lombardo, R. (2007) Baseline Water Quality and Macrophytes Assemblages in Pampean Streams: A Regional Approach. Water Research, 41, 1399-1410. http://dx.doi.org/10.1016/j.watres.2006.08.026

[10] Nurminen, L.K.L. and Horppila, J.A. (2002) A Diurnal Study on the Distribution of Filter Feeding Zooplankton: Effect of Emergent Macrophytes, pH and Lake Trophy. Aquatic Sciences, 64, 198-206.

[11] Giorgi, A., Feijoó, C. and Tell, G. (2005) Primary Producers in a Pampean Stream: Temporal Variation and Structuring role. Biodiversity and Conservation, 14, 1699-1718. http://dx.doi.org/10.1007/s10531-004-0694-z

[12] Wiley, M.J. and Kohler, S. (1980) Positioning Changes of Mayfly Nymphs Due to Behavioral Regulation of Oxygen Consumption. Canadian Journal of Zoology, 58, 618-622. http://dx.doi.org/10.1139/z80-088

[13] Ferreiro, N.A., Feijoó, C., Giorgi, A. and Leggieri, L. (2011) Effects of Macrophyte Heterogeneity and Food Availability on Structural Parameters of the Macroinvertebrate Community in a Pampean Stream. Hydrobiologia, 664, 199-211. http://dx.doi.org/10.1007/s10750-010-0599-7 
Scientific Research Publishing (SCIRP) is one of the largest Open Access journal publishers. It is currently publishing more than 200 open access, online, peer-reviewed journals covering a wide range of academic disciplines. SCIRP serves the worldwide academic communities and contributes to the progress and application of science with its publication.

Other selected journals from SCIRP are listed as below. Submit your manuscript to us via either submit@scirp.org or Online Submission Portal.
